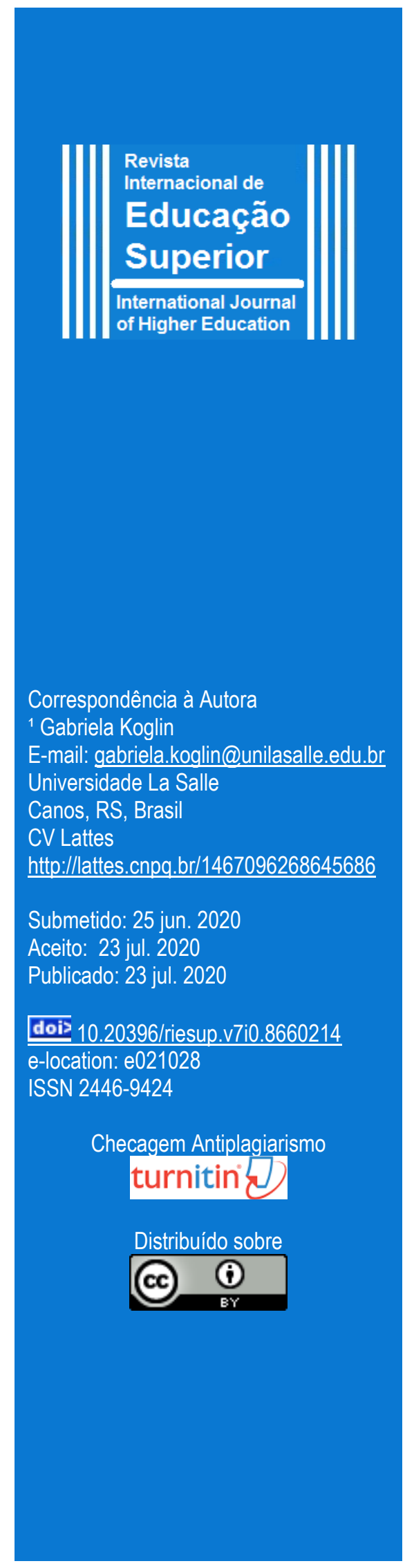

\title{
Estudantes Universitários e as Percepções de Seus Estilos de aprendizagem
}

Gabriela Koglin ${ }^{1}$ iD https://orcid.org/0000-0001-8876-9137

Marina Ortolan Arald ${ }^{2}$ (iD) https://orcid.org/0000-0001-5649-5135

Vera Lucia Felicetti 3 id https://orcid.org/0000-0001-6156-7121

1,2,3 Universidade La Salle

RESUMO

Em um universo de avanço da tecnologia a aula universitária precisa se reinventar. Sendo assim, para compreender se estudantes se beneficiam ao reconhecer seu estilo de aprendizagem (EA) e a partir disso, aprendem com técnicas específicas correspondentes a cada estilo, foram realizadas intervenções em disciplinas dos cursos de Psicologia e Nutrição em uma universidade comunitária na região metropolitana de Porto Alegre - RS. No total, participaram 22 estudantes que foram avaliados através do Levantamento das Preferências Perceptuais em Estilos de Aprendizagem de Joy Reid. Achados revelam que 57\% dos estudantes participantes têm estilo de aprendizagem do tipo auditivo. A partir de abordagens interventivas distintas em sintonia com os estilos de aprendizagens dos estudantes, a grande maioria deles se beneficiou e respondeu positivamente aos métodos propostos.

\section{PALAVRAS-CHAVE}

Estudante universitário. Estilos de aprendizagem. Métodos de ensino. 


\section{College Students and Perceptions of Their Learning Styles}

\section{ABSTRACT}

In a universe with advancing technology, the college class needs to reinvent itself. Therefore, in order to understand whether students benefit from recognizing their learning style (LS) and, consequently, learning with specific techniques corresponding to each style, interventions were carried out in courses in the Psychology and Nutrition programs in a non-profit university in the metropolitan region of Porto Alegre - RS. Overall, 22 students participated in an evaluation using the Perceptual Learning Styles Preferences Inventory by Joy Reid. The findings reveal that $57 \%$ of the participating students have an auditory learning style. Based on the interventional approaches in line with the students' learning styles, the large majority of them benefited and responded positively to the proposed methods.

\section{KEYWORDS}

College students. Learning styles. Teaching methods.

\section{Estudiantes Universitarios y las Percepciones de Sus Estilos de Aprendizaje}

\section{RESUMEN}

En un universo de tecnología avanzada, la clase universitaria necesita reinventarse. Por lo tanto, para comprender si los estudiantes se benefician al reconocer su estilo de aprendizaje (AE) y de eso, aprender con técnicas específicas correspondientes a cada estilo, se realizaron intervenciones en asignaturas de los cursos de Psicología y Nutrición en una universidad comunitaria de la región metropolitana. de Porto Alegre - RS. En total, participaron 22 estudiantes que fueron evaluados a través de la Encuesta de preferencias perceptivas de Joy Reid en estilos de aprendizaje. Los resultados revelan que el $57 \%$ de los estudiantes participantes tienen un estilo de aprendizaje auditivo. Desde diferentes enfoques de intervención en línea con los estilos de aprendizaje de los estudiantes, la gran mayoría de ellos se beneficiaron y respondieron positivamente a los métodos propuestos.

\section{PALABRAS CLAVE}

Estudiante de pregrado. Aprendiendo estilos. Métodos de enseñanza. 


\section{Introdução}

Com a facilidade no acesso à tecnologia e informação e, considerando a aprendizagem na Educação Superior baseada em competências, se evidencia a necessidade de mudanças nos processos de ensino e de aprendizagem. Assim, se faz necessário melhor compreender qual o meio mais eficaz para ensinar de modo que o estudante melhor aprenda. Isto se justifica, pois formar um profissional competente, que aprenda o conteúdo e possa aplicá-lo de maneira eficiente quando estiver em sua prática profissional é o objetivo central de qualquer formação acadêmica. A partir disso, diversos autores se propuseram a pesquisar sobre estilos de aprendizagem e como o estudante pode se beneficiar de um ensino que tenha atenção aos seus estilos, o que pode gerar maior aproveitamento do tempo em sala de aula (BARROS, MONTERIO e MOREIRA, 2014; NEGREIROS et al., 2016; SONAGLIO et al., 2013).

O processo de aprendizagem vem sendo estudado (BECKER, 2012; DEWEY, 1971; FREIRE, 2003; MORIN, 2005; REGO, 2001; REID, 1987) há muito tempo e são diversas as abordagens que estabelecem conceitos como, por exemplo, a forma como cada indivíduo se comporta ao assimilar informações, a maneira como as interpreta, as dificuldades que enfrenta para entender o que lhe foi apresentado, que recursos prefere utilizar e quais os métodos que dispõe.

Nesta direção, como evidencia (2011, p.77), “[...] saber como se aprende permite uma aprendizagem de melhor qualidade, pois o ensino pode se tornar mais eficaz. Logo, ensinar e aprender são dois construtos intimamente ligados." Assim, estudar os Estilos de Aprendizagem (EA) tem por objetivo perceber as características pessoais do indivíduo e os condicionantes ao seu redor (DUNN e DUNN, 1999). Conhecer os estilos de aprendizagem dos estudantes permite, segundo Felicetti (2011), descrever melhores condições de ensino, oportunizando, assim, diferentes abordagens educativas de modo a melhor responder as necessidades de aprendizagem de cada um. Tais estilos são compreendidos com base na revisão de textos, com nomes importantes da área que ajudam a compreender e classificar os EA (NEGREIROS et al., 2016).

Estilos de aprendizagem são processos individuais utilizados para a compreensão e retenção da informação, gerando ganho de conhecimentos ou habilidades. Assim, professores necessitam encontrar maneiras adequadas para que os processos de ensino e de aprendizagem ocorram, ao adotarem estratégias de ensino mais próximas dos estilos de aprendizagem dos estudantes para estimular e manter um bom desempenho deles (JESUS et al., 2017).

$\mathrm{Na}$ Educação Superior, a metodologia usada pelo professor pode intervir, tanto como facilitador ou não no processo de aprendizagem. A passagem do Ensino Médio para o superior rompe com a estrutura comportamental de outrora que, agora na Educação Superior requer outra forma de agir e ser estudante. Exige uma autonomia, quer seja ela de estudos ou comportamentos, visto que o desenvolvimento do estudante, nesse grau de ensino busca o senso crítico e comprometimento com os estudos, aspectos estes com os quais eles têm dificuldades devido a cultura do Ensino Médio e a não aproximação ou conhecimento do seu estilo próprio de aprender.

\begin{tabular}{l|l|l|l|l|l}
\hline (C) Rev. Inter. Educ. Sup. & Campinas, SP & v.7 & $1-15$ & e021028 & 2021 \\
\hline
\end{tabular}


Um fator relevante na formação de profissionais da área da saúde é a capacidade do professor relacionar conhecimento teórico com a prática que ele tem enquanto profissional. A possibilidade de o estudante visualizar a atuação profissional ao mesmo tempo em que adquire o conhecimento teórico, permite melhor desenvolver o conhecimento. Porém, por vezes se destaca a relevância que há do conhecimento em detrimento da metodologia de ensino aplicada (ZANON, OLIVEIRA \& QUEIROZ, 2009).

A proposta aqui apresentada tem como princípio a motivação dos pesquisadores em conhecer melhor o seu estudante. Inquietação essa que se intensificou após a conclusão dos módulos relacionados ao ensino e aprendizagem de um curso de pós-graduação direcionado para professores. A atualização dos currículos da universidade em questão também foi um forte incentivo para que se buscasse conhecer mais o estudante e se propusesse esta pesquisa, tendo em vista a aplicação de métodos de ensino mais direcionados aos estilos de aprendizagem dos estudantes, bem como possibilitar que a eles, através do autoconhecimento, tenham um melhor desempenho acadêmico. Portanto, o objetivo central deste trabalho foi: compreender se estudantes se beneficiam ao reconhecer seu estilo de aprendizagem (EA) e a partir disso, aprendem com técnicas específicas correspondentes a cada estilo

O estudo dos estilos de aprendizagens serve para trabalhar as diferenças de estilos que são inferiores ou indiferentes de cada estudante conforme a sua subjetividade (NEGREIROS et al., 2016), bem como propor métodos que sejam mais adequados à população estudada, para que haja uma aprendizagem mais significativa. A proposta de intervenção baseada nos diferentes estilos de aprendizagem possibilita o respeito à individualidade dos estudantes o que favorece sua centralidade no processo, a criação de um ambiente que favorece o autoconhecimento e a consciência de que os estudantes aprendem de formas diferentes e isso pressupõe a exploração de distintas estratégias de trabalho por parte dos docentes (TAPIAS et al., 2011). Para conhecer qual estilo é utilizado pelo estudante podem ser utilizados questionários estruturados, como o proposto por Reid (1987) ao estudar universitários norteamericanos. Nesta direção, apresenta-se a metodologia delineada a este estudo que fez uso do proposto inicialmente por Reid (1987).

\section{Metodologia}

O presente estudo trata de uma abordagem prospectiva que visa identificar os estilos de aprendizagem dos estudantes de duas turmas, uma do curso de Nutrição e outra do curso de Psicologia de uma universidade localizada na região metropolitana de Porto Alegre, Rio Grande do Sul.

Foi aplicado o Levantamento das Preferências Perceptuais em Estilos de Aprendizagem de Joy Reid (1987) que identifica aprendizes visuais, auditivos, cinestésicos, táteis e se o aprendizado é preferencialmente em grupos ou de maneira individual. O questionário é autoaplicável e foi construído a partir de 30 questões, com respostas que variam em uma 
escala likert $^{1}$ de cinco alternativas, entre concordo plenamente a discordo totalmente. Mazuroski Jr et al. (2008) utilizaram o mesmo questionário e descreveram cada um dos estilos (Quadro 1) de aprendizagem sob os quais o questionário foi baseado.

Quadro 1. Descrição dos estilos de aprendizagem segundo Mazuroski Jr et al (2008)

\begin{tabular}{|l|l|}
\hline Visual & $\begin{array}{l}\text { Aprende melhor vendo as palavras em livros, no quadro e em livros de exercícios. Lembra e } \\
\text { compreende informações e instruções melhor se as ler. Não precisa de tanta explicação oral e } \\
\text { consegue muitas vezes aprender sozinho com o livro. Deve tomar notas de aulas expositivas, } \\
\text { palestras e instruções orais, se quiser se lembrar das informaçôes. }\end{array}$ \\
\hline Auditiva & $\begin{array}{l}\text { Aprende ouvindo as palavras faladas e através de explicações orais. Pode se lembrar de } \\
\text { informações lendo-as em voz alta, ou movendo seus lábios enquanto lê, especialmente } \\
\text { quando está estudando matéria nova. Beneficia-se de ouvir gravações, palestras e discussões } \\
\text { em classe. Também se beneficia de produzir gravações para ouvi-las depois, de ensinar para } \\
\text { os colegas, e de conversar com professores. }\end{array}$ \\
\hline Cinestésica & $\begin{array}{l}\text { Aprende melhor pela experiência, envolvendo-se fisicamente nas experiências de sala de } \\
\text { aula. Se lembra bem de informações quando participa ativamente de atividades, aulas de } \\
\text { campo, e de dramatizações durante a aula. Combinações de estímulos - por exemplo, uma } \\
\text { gravação em áudio juntamente com uma atividade - ajudam a compreender matéria nova. }\end{array}$ \\
\hline Tátil & $\begin{array}{l}\text { Aprende melhor quando tem a oportunidade de participar em experiências nas quais "põe as } \\
\text { mãos" nos materiais. Fazer experiências num laboratório, manusear e construir modelos, } \\
\text { tocar e trabalhar com materiais fornecem as melhores situações de aprendizagem. Fazer } \\
\text { anotações ou escrever instruções pode ajudar a se lembrar de informações, e o envolvimento } \\
\text { físico nas atividades escolares podem ajudar a compreender matéria nova. }\end{array}$ \\
\hline Grupal & $\begin{array}{l}\text { Aprende mais facilmente e tem mais sucesso nos exercícios quando estuda com pelo menos } \\
\text { mais um colega. Valoriza a integração com o grupo e o trabalho em aula com colegas e se } \\
\text { lembra melhor das informações quando trabalha com dois ou três colegas. O estímulo que } \\
\text { recebe do trabalho em grupo a ajuda a aprender e compreender novas informaçôes. }\end{array}$ \\
\hline Individual & $\begin{array}{l}\text { Aprende melhor quando trabalha sozinho, pensa melhor quando estuda sozinho e se lembra } \\
\text { das informações que aprende sozinho. Entende melhor a matéria quando a aprende sozinho e } \\
\text { progride mais na aprendizagem quando trabalha sozinho. }\end{array}$ \\
\hline
\end{tabular}

Fonte: Adaptado de Mazuroski Jr et al. (2008).

Após a coleta, os dados foram analisados de acordo com a pontuação utilizada por Mazuroski Jr. et al. (2008), onde as preferências de aprendizagem são classificadas como principais (de 38-50 pontos), menores (de 25-37 pontos) e indiferentes (de 0-24 pontos). Os estilos de aprendizagem menores indicam áreas em que o estudante pode operar bem como aprendiz, aprendendo de várias maneiras diferentes e, portanto, pode ser interessante experimentar essas formas. Já os estilos de aprendizagem indiferentes indicam que o estudante pode ter dificuldade em aprender daquela maneira. Neste caso pode-se direcionar a aprendizagem aos seus estilos mais dominantes ou tentar desenvolver algumas das habilidades que podem aperfeiçoar os estilos de aprendizagem em áreas indiferentes.

\footnotetext{
${ }^{1}$ Escala likert: habitualmente usada em pesquisas de opinião, aonde ao responderem o questionário os entrevistados especificam o seu nível de concordância ou não com a afirmação. (LUDWIG, et al, 2015, p.09)
} 
De acordo com Reid (1987) os estudantes deveriam ter a oportunidade de se avaliar em relação aos estilos de aprendizagem e de serem encorajados a diversificar suas preferências. Ou seja, não necessariamente o estudante deva utilizar ou ser submetido apenas aos estilos avaliados como preferidos. Pode ser enriquecedora a experiência com outros estilos de aprendizagem se bem conduzida por docente atento.

Concluída esta etapa, foram utilizadas estratégias de ensino em acordo com os estilos identificados e, após esta intervenção, os estudantes foram questionados quanto a referida estratégia, verificando se foram adequadas e se resultaram em maior aprendizado.

As turmas foram escolhidas por serem disciplinas em que as autoras estavam atuando quando do surgimento da questão de pesquisa. Optou-se por manter as abordagens de acordo com cada perfil de curso, utilizando as ferramentas usuais de cada disciplina e professora.

A proposta foi aplicada no curso de Psicologia com os estudantes da disciplina de História e Bases Epistemológicas da Psicologia, alocada no primeiro semestre do curso que tinha 30 estudantes matriculados. A turma se caracterizou por ser um grupo participativo e de apoio mútuo, e tiveram uma relação amistosa e cooperativa com a professora durante o semestre. O questionário sobre as preferências de aprendizagem foi aplicado e avaliado em sala de aula e os estudantes foram informados sobre a atividade interventiva que iria ocorrer no decorrer do semestre.

O questionário utilizado pelo curso de Nutrição foi construído no Google Forms e disponibilizado na plataforma Google Classroom, utilizada como ferramenta pela disciplina Técnica Dietética II, do quarto semestre do curso. Os 20 estudantes matriculados foram convidados verbalmente e através da plataforma Google Classroom a responder às questões. O resultado da análise realizada foi enviado por e-mail a cada um dos estudantes, individualmente.

\section{Aplicação do Questionário}

A intervenção feita pelo curso de Psicologia, foi realizada em uma Shared Business, uma sala de visual arrojado, favoreceu a criatividade e o trabalho em grupo. Ao chegar à sala, os estudantes encontraram uma mesa com diversos post-its coloridos, chromebooks, massinha de modelar, canetas, lápis de cor e folhas, material que seria utilizado na atividade. Participaram da intervenção 11 estudantes, sendo que uma delas teve que sair da aula antes da conclusão da atividade, portanto foi desconsiderada.

No dia da intervenção, nos primeiros 25 minutos da aula do curso de Psicologia, aplicou-se o instrumento aos estudantes que não estavam presentes na data anterior. Após a aplicação, iniciou-se uma aula expositiva dialogada sobre as tendências modernas da Psicologia com duração de 1 hora e 30 minutos. Para continuidade da intervenção, os estudantes fizeram o levantamento do instrumento, (re)conhecendo seu estilo de aprendizagem, o que está apresentado no Quadro 2 que segue. 
No curso de Nutrição, 20 estudantes responderam à pesquisa sobre seus estilos de aprendizagem e, os resultados constam no Quadro 3.

\section{Resultados e Discussão}

Como pode ser observado no Quadro 2, sete estudantes (70\%), apresentaram prevalência pelo método auditivo, sendo em cinco (50\%) situações o preponderante; seis (60\%) apresentaram o cinestésico, sendo em três (30\%) o mais relevante; e quatro (40\%) tiveram o perfil tátil, sendo o mais prevalente em duas (20\%) alunas. Quando analisada a prevalência no estilo grupal ou individual, cinco (50\%) estudantes aprendem melhor através do grupo e dois (20\%) de maneira individual.

Foi lido pela professora o que cada um destes estilos representa para que os estudantes pudessem compreender a proposta do exercício que viria na sequência da aula. Ao final da leitura os estudantes comentaram que eles se identificavam com a conclusão sugerida pelo levantamento. Apenas uma aluna que apresentava alta prevalência no estilo tátil e média no estilo sinestésico imaginou que este segundo lhe parecia mais acentuado.

Quadro 2. Descrição dos estilos de aprendizagem (principais e indiferentes) da amostra do curso de Psicologia $(n=10)$.

\begin{tabular}{|l|l|l|}
\hline ESTUDANTES & PRINCIPAIS & INDIFERENTES \\
\hline 1. Homem & Sem preferências, equilíbrio nas respostas & Tátil \\
\hline 2. Homem & Auditivo, Cinestésico, Grupal & - \\
\hline 3. Mulher & Auditivo, Individual & - \\
\hline 4. Mulher & Auditivo, Cinestésico, Grupal & - \\
\hline 5. Mulher & Auditivo & - \\
\hline 6. Homem & Cinestésico, Auditivo, Tátil, Grupal & \\
\hline 7. Mulher & Cinestésico, Individual, Tátil, Auditivo & Grupal, Visual \\
\hline 8. Mulher & Tátil, Visual e Cinestésico & Grupal \\
\hline 9. Mulher & Tátil, Grupal e Auditivo & - \\
\hline 10. Homem & Cinestésico e Grupal & - \\
\hline
\end{tabular}

Fonte: Os autores, 2020.

Ainda acerca dos estudantes do curso de Psicologia, eles se reuniram em grupos de acordo com seu estilo de aprendizagem: cinco integrantes do grupo auditivo, três do sinestésico e dois do tátil. A estudante $\mathrm{n}^{\circ} 3$ apresentou predileção pelo trabalho individual, portanto foi sugerido que desenvolvesse a atividade desta maneira. Porém, ao iniciar, ela decidiu se unir com o restante do grupo. $\mathrm{O}$ estudante $\mathrm{n}^{\circ} 1$ apresentou resultados menores e 
semelhantes em todos os métodos de aprendizagem o que indica que qualquer uma das áreas o favorece como aprendiz, exceto a tátil, a qual teve pontuação indiferente. Este estudante apresentou maior pontuação no grupo auditivo, portanto desenvolveu a atividade com eles.

Entre os 20 estudantes da disciplina do curso de Nutrição, 12 (60\%) responderam à pesquisa sobre os estilos de aprendizagem e os resultados estão descritos no Quadro 3.

Quadro 3. Descrição dos estilos de aprendizagem (principais e indiferentes) da amostra do curso de Nutrição $(n=12)$.

\begin{tabular}{|l|l|l|}
\hline ESTUDANTE & PRINCIPAIS & INDIFERENTES \\
\hline 1. Mulher & Individual, Auditivo e Cinestésico & - \\
\hline 2. Mulher & Grupal, Auditivo, Cinestésico/Visual & Individual \\
\hline 3. Mulher & Individual e Visual & Grupal \\
\hline 4. Mulher & Individual, Cinestésico, Auditivo & - \\
\hline 5. Mulher & Individual e Visual & Grupal \\
\hline 6. Homem & Auditivo, Cinestésico & - \\
\hline 7. Mulher & Cinestésico, Auditivo e Individual & - \\
\hline 8. Mulher & Cinestésico, Tátil e Visual & - \\
\hline 9. Homem & Auditivo e Visual & - \\
\hline 10. Mulher & Individual e Auditivo & Grupal \\
\hline 11. Mulher & Todos (principais: cinestésico e tátil) & - \\
\hline 12. Mulher & Tátil, Grupal, Cinestésico, Auditivo & Individual \\
\hline
\end{tabular}

Fonte: os autores.

A preferência por métodos auditivos de aprendizagem foi apontada por $9(75 \%)$ estudantes do curso de Nutrição. Após, vieram as preferências Cinestésica (8; 66,7\%), Individual (7; 58,3\%) e Visual (6;50\%). As preferências com menor representatividade nesta turma foram a Grupal e Tátil, que estavam presentes em apenas 3 (25\%) deles.

Com relação aos estilos considerados indiferentes pelas duas turmas, $8(36,36 \%)$ estudantes apresentaram escore menor que 24 para alguma forma de aprendizagem, sendo 5 $(22,72 \%)$ com dificuldade em métodos Grupais, 2 (9,1\%) para métodos Individuais e 1 $(4,54 \%)$ para métodos Táteis e Visuais.

Pesquisas de Dunn e Dunn (1979) envolvendo estudantes mostraram que apenas 20$30 \%$ dos jovens estudantes eram aprendizes auditivos, $40 \%$ visuais e $30-40 \%$ táteis/cinestésicos, visuais/táteis, ou outra combinação. Os resultados diferiram dos encontrados nesta pesquisa. Muitos intervenientes podem ser conjecturados, entre eles aspectos relacionados ao vasto repertório midiático que permeia a contemporaneidade, diferentemente do que ocorria em anos passados quando dos estudos de Dunn e Dunn. Ao 
encontro da explicação para a diferença entre as pesquisas, Dorsey e Pierson (1984) concluíram que a idade e experiências de trabalho influenciam as preferências de aprendizagem e que, especialmente depois dos 33 anos a preferência mais aparente é a cinestésica.

Reid (1987), em seus estudos em universidades norte-americanas encontrou forte preferência por estilos de aprendizagem cinestésicos e táteis, ao mesmo tempo em que a aprendizagem em grupo se mostrou negativamente associada. Estes resultados foram semelhantes aos observados nesta pesquisa, onde 14 (63,6\%) estudantes preferiram estilos cinestésicos e o maior número de estilos considerados indiferentes também foram os Grupais, representados por $5(22,72 \%)$ estudantes. A autora também separou as preferências de acordo com a área de estudo do estudante e verificou que apenas os que eram de cursos das ciências da natureza foram classificados como aprendizes visuais, enquanto os estudantes da área de humanas foram os menos orientados neste sentido. Da mesma forma foi visto que dentre os estudantes do curso de Psicologia não houve preferência pela aprendizagem visual $(\mathrm{n}=1 ; 10 \%)$.

Ainda de acordo com Reid (1987) as áreas mais relacionadas ao estilo de aprendizagem auditivo foram: ciências da computação, ciências da natureza, negócios e medicina, vindo ao encontro do observado no curso de Nutrição $(n=9 ; 75 \%)$. Engenharias e ciências da computação foram significativamente mais táteis do que os estudantes de humanas nos estudos de Reid (1987). A referida autora demonstrou que, exceto os estudantes de ciências da natureza, os demais indicaram que a aprendizagem individual foi o estilo menos preferido. $\mathrm{Na}$ presente pesquisa o estilo grupal (Psicologia $\mathrm{n}=5 ; 50 \%$ versus Nutrição $\mathrm{n}=3 ; 25 \%$ ) prevaleceu sobre o individual (Psicologia $n=1 ; 10 \%$ versus Nutrição $n=7 ; 58,3 \%$ ) apenas no curso de Psicologia.

\section{Intervenção}

A partir da análise do estilo de aprendizagem, acima apresentado, foi proposto que os estudantes da turma de Psicologia pudessem imaginar, com base na história da psicologia (conteúdo de toda disciplina - passado) e nas tendências modernas (atualidade, novas possibilidades do fazer psi - presente), como estará o mercado de trabalho, os desafios e possibilidades de atuação deles quando formados (futuro). Cada grupo deveria seguir uma conduta de acordo com sugestões da professora que visava viabilizar a aprendizagem para aquele perfil identificado na análise prévia. Ao final da discussão com o grupo, que teve uma hora de duração, a turma se reuniria novamente para uma mesa redonda.

O grupo auditivo ficou reunido na Shared Businnes sentado em cadeiras ao redor de uma mesa circular que favorecia o contato visual. Foi sugerido que o grupo lesse em voz alta um texto publicado na década de 1990 sobre a atuação do psicólogo, acompanhando a leitura com o dedo, que ao fundo tocasse uma música instrumental e que eles desenvolvessem uma discussão sobre o assunto. Para iniciar a atividade, uma aluna sugeriu uma música clássica e 
comentou que estava acostumada a estudar assim em casa. Outros dois estudantes comentaram que esta não era uma prática comum para eles. Inicialmente, o grupo começou lendo o texto de maneira individual, sem vocalizar. Passados dez minutos, a maioria não havia conseguido avançar muito na leitura. A aluna que sugeriu a música comentou que esta estava lhe distraindo, pois ao invés de ler o texto, estava atenta à melodia, a qual apreciava muito. Os demais relataram não ter percebido a música. Neste momento, uma das alunas disse que se concentrava mais quando alguém lia para ela, então um colega do grupo sugeriu ler em voz alta. Assim, eles concluíram a leitura rapidamente e espontaneamente passaram a discutir os aspectos que o texto suscitou neles. A discussão se aprofundou e gerou o resultado esperado, com o envolvimento de todos os estudantes. O grupo foi capaz de extrapolar o objetivo da atividade, contextualizando sua fala com o conhecimento adquirido em outras disciplinas cursadas. O grupo se mostrou bastante autônomo, não percebendo a presença do professor por perto. No momento da apresentação, o grupo optou por contar aos colegas o que havia discutido.

O grupo cinestésico era composto por três estudantes, sendo um deles o estudante mais participativo das aulas durante o semestre. Foi indicado que eles desenvolvessem a atividade em uma sala que contava com poltronas confortáveis e um tapete macio, além de uma mesa de reunião com diversas cadeiras. Para este grupo foi sugerido que eles se sentassem nas cadeiras ou no tapete de maneira que ficassem confortáveis e que fizessem pequenas pausas frequentes. $\mathrm{O}$ grupo iniciou a atividade nas poltronas, mas preferiu se deslocar para a mesa de reunião, mantido na ponta da mesa este estudante de destaque. A dica de realizar os intervalos não foi seguida. A tarefa do grupo era criar algo prático que discutisse o tema da aula. Apesar de aplicados na discussão, eles encontraram dificuldade para criar algo a partir dela. Em todos os momentos que a professora passava para verificar a atividade, eles buscavam comentar algo ou pedir sua opinião. A discussão foi realizada de forma rápida e pouco aprofundada, tendo o grupo demonstrado maior preocupação no que iria apresentar para a turma. Este foi o grupo que ficou mais disperso da atividade. Dois estudantes colaboraram mais enquanto o estudante destaque participava apenas quando a professora se aproximava. Sem ideia de como seguir, o grupo requisitou a presença da professora, que sugeriu que eles criassem algo com a massinha de modelar ou desenvolvessem uma breve pesquisa on-line, com a utilização do chromebook para organizar os percentuais e apresentar os dados. A partir disso, eles elaboraram um questionário que foi enviado para conhecidos por WhatsApp, conseguindo um total de 20 respondentes. Neste momento de elaboração da pesquisa e desenvolvimento prático da atividade, o grupo mostrou-se mais organizado e focado. Para entender o modo de funcionamento do grupo é importante compreender a posição que o estudante de destaque ocupou na turma. Entende-se que suas atitudes criaram expectativas nos colegas que contavam com sua participação e liderança e, por não o ter feito e ninguém mais assumir esse lugar, o grupo ficou sem conseguir focar na atividade no seu início. No momento da apresentação o grupo utilizou gráficos para apresentar a pesquisa e comentou os principais resultados. Foi perceptível que o estudante destaque tentou se engajar mais nesse momento, porém, não conseguiu se aprofundar na discussão da pesquisa. 
O grupo tátil foi deslocado para um espaço que contava com uma mesa alta redonda e banquetas e ficava ao lado das outras duas salas. Ele era composto por uma aluna jovem que é bastante participava nas aulas e outra aluna de mais idade e de conduta mais reservada. A proposta era que elas desenvolvessem uma atividade manual para apresentar aos colegas. Este grupo teve funcionamento mais complexo que os demais, pois as alunas não pareciam conseguir se expressar de forma clara e chegar a um consenso. A partir de sugestões da utilização de massinha de modelar e da ideia de desenvolver um jogo, ambas se interessaram pela segunda opção. A estudante mais comunicativa assumiu a tarefa, desenvolvendo-a praticamente sozinha. Ela propôs e executou um jogo da memória feito de post-its com perguntas e respostas sobre a história da psicologia.

Após a conclusão da intervenção, os estudantes foram convidados a dar um feedback da aula a partir de algumas perguntas que foram respondidas individualmente. Quando questionados sobre como se sentiram, todos responderam positivamente, como por exemplo, "melhor do que o esperado" (estudante $\mathrm{n}^{\mathrm{o}} 3$ ), e que foi necessário "sair da zona de conforto" (estudante $\mathrm{n}^{\circ} 6$ ). A estudante que foi a líder do grupo tátil revela que:

No início me senti bem animada, me pareceu divertido e desafiador. Ao receber as
instruções, confirmei meus primeiros pensamentos. O momento mais desafiador foi
o de conseguir conexão com a colega. Quanto ao desenrolar da atividade, objetivo,
regras... após estabelecer, adorei a parte de criação. (Estudante no 8 )

Todos os estudantes do grupo auditivo indicaram que a discussão em grupo foi parte importante do processo, tendo um dos estudantes descoberto durante a experiência que este meio de aprender lhe favorecia. Dois estudantes revelaram que a música os distraiu no momento de leitura. Um deles colocou fone de ouvido e escutou outra música, o que facilitou a leitura do texto. Quando questionados se os estudantes costumam utilizar este tipo de atividade para estudar, a maioria sinalizou que não e ao apontar se a atividade assim parecia mais fácil ou mais difícil, a fala da aluna expõe o pensamento da maioria: "considero fácil. Me identifiquei muito em vários momentos da atividade, o aprendizado acabou se tornando mais natural." (estudante $\mathrm{n}^{\mathrm{o}}$ 5). Quando questionados se o modo como seu grupo desempenhou a atividade ajudou quando comparado a outros meios de aprendizagem mais usuais em aula, apenas dois sinalizaram que foi indiferente: "Gostei do modo que aprendemos, porém também gosto bastante de aprender com um professor 'ensinando"(estudante $n^{\circ} 5$ ) e "Sim, me ajudou. Principalmente o debate, pois me passaram algumas ideias e pontos de vista" (estudante $\mathrm{n}^{\circ} 2$ ).

Diante dos resultados das preferências de aprendizagem dos estudantes da turma de Nutrição foi planejada uma aula que levou em consideração os seguintes pontos: atividades individuais, auditivas e cinestésicas, visto que foram as mais relacionadas com esta turma. A duração da aula foi de 3 horas, contabilizando o intervalo e contou com: aula expositivadialogada, podcast, vídeo, pesquisa em site com smartphones, uso do site Mentimeter para formação de nuvem de palavras e atividade de sensibilização com a criação de mensagem para um possível paciente. Ao final da aula foi solicitado que os estudantes presentes $(n=11)$ respondessem às seguintes questões: 
- O que você achou das atividades de hoje (Mentimeter, Podcast, Site, Escrever mensagem para um paciente, Vídeos, Aula Expositiva Dialogada)? Justifique.

- Como você costuma estudar? Que tipo de atividades utiliza?

É importante destacar que, para não constranger o estudante, as respostas não foram identificadas.

A primeira questão teve por objetivo saber se os métodos escolhidos realmente favoreceram o interesse do estudante. $\mathrm{O}$ uso do Mentimeter, plataforma sueca que possibilita interatividade durante apresentações, era conhecida por poucos estudantes e o retorno foi positivo, sendo considerada interessante e "muito legal", permitindo visualização e entendimento dos assuntos debatidos em aula além de permitir a exposição de opinião e que deveria ser mais utilizada, pois tem muito potencial a ser explorado já que os estudantes usam muito o celular. Apenas um estudante disse que achou legal, mas não viu o benefício da atividade.

Com relação ao podcast, foi colocado um áudio para que todos ouvissem juntos. A atividade foi considerada dinâmica, uma excelente maneira de trazer bom conteúdo e que dependendo do tema pode chamar a atenção. Dois estudantes disseram que gostariam de visualizar o conteúdo, não só escutar, possivelmente se enquadrando na classificação de preferência visual de aprendizagem. Foi sinalizado que o podcast poderia ser mais curto e isso foi perceptível na aula, quando, após 8 minutos a turma começou a ficar dispersa (o tempo total eram 12 minutos).

O uso da pesquisa em site não era novidade para os estudantes e as respostas relacionaram-se ao site específico que foi usado, com destaque para as observações de que trouxe atualidade e que pode ser útil dependendo da área de desejo profissional. Isto sinaliza a importância das atividades e exemplos utilizados em sala de aula estarem em consonância com a profissão em estudo para que desperte o interesse do estudante. Um estudante relatou que não gostou muito, pois não gosta de estudar pela internet.

A atividade que usou a escrita de mensagem para um paciente internado receber junto com a refeição (a aula abordava a alimentação hospitalar) recebeu muitos elogios, sendo considerada "muito bacana”, fantástica, "bem legal”, possibilitou demonstrar os sentimentos e refletir, o que permitiu que o estudante se sentisse no lugar do paciente (alguns receberam a mensagem). Outras avaliações disseram que foi uma boa ideia para ser usada na prática e que mais atividades assim seriam bem-vindas. Apenas um estudante disse não ter gostado muito.

O vídeo mostrado tinha o intuito que os estudantes vissem como a alimentação hospitalar é tratada como prioridade em alguns lugares como a Suíça, e por isso era em francês, mas o objetivo era que observassem o preparo da alimentação e a montagem dos pratos. Ainda assim a questão linguística e cultural foi apontada por alguns estudantes: "vídeo de $1^{\circ}$ mundo, poderia trazer os dois lados", "teve o empecilho da língua, tirou a atratividade", "apesar de o vídeo estar em francês estava interessante". Um estudante pontuou que faltou 
uma visita a um hospital para conhecerem a realidade. Mas ele também foi positivo para outros, sendo considerado ótimo e interessante, pois permitiu a visualização de possíveis práticas para tornar o alimento mais atrativo para o paciente e trouxe um conteúdo novo e muitas ideias de preparo, além de ser visual.

A aula expositiva dialogada foi considerada positiva por todos. Elogios como criativa, dinâmica e sempre com algo diferente nas atividades propostas. A utilização de recursos visuais junto com a exposição foi bem recebida e produtiva para memorização. Um estudante comentou que gostou, pois aprecia debate e outro "é bom para perdermos a vergonha de falar". O uso mais frequente das ferramentas usadas foi solicitado por serem bem instigantes.

A segunda questão corroborou com o resultado do questionário, pois a grande maioria dos estudantes respondeu que estuda sozinha e apenas 2 responderam que, para auxiliar um colega podem estudar em dupla ou grupos. O uso de música de fundo enquanto estudam também foi citado por 2 estudantes. Cerqueira (2000) em sua tese de doutorado sobre estilos de aprendizagem em universitários comenta acerca dos estudos de Rita e Kenneth Dunn onde um dos estímulos ambientais para aprendizagem é o som e que há variabilidade entre as preferências dos estudantes, com alguns preferindo o silêncio absoluto enquanto outros parecem se beneficiar de música ou sons da televisão.

As atividades utilizadas para estudo variaram: material que os professores passam, sites de pesquisa, vídeos, construção de resumos e esquemas, leitura de livros, escutando áudios/podcast. Com exceção de um estudante, os demais citaram duas ou mais formas de estudar. Chamou a atenção que vários usam a internet e um estudante relatou apenas usar a internet para estudar. Também é importante destacar que um estudante escreveu que busca maneiras simples e descontraídas de aprender e outro disse que quanto mais interativa e dinâmica a aula é, melhor. Esses relatos podem ser um indicativo para aulas que envolvam diferentes estratégias de ensino-aprendizagem.

\section{Conclusões}

A partir da intervenção realizada, foi possível identificar que a maioria dos estudantes se favorecem de uma aprendizagem auditiva $(57,15 \%)$. Também se verificou a dificuldade dos estudantes em se colocarem em uma posição mais ativa de aprendizagem, visto que o melhor funcionamento ocorreu no grupo de conduta mais passiva, a qual estão habituados desde o início do processo de aprendizagem.

Foi possível perceber a preferência por aulas dinâmicas, que envolvam diversas atividades, principalmente auditivas e que os estudantes possam realizar sozinhos. Os estudantes auditivos, na intervenção realizada no curso de Psicologia, corroboraram positivamente a escuta da música instrumental. Boa parte deles não havia experimentado estudar dessa maneira e concluíram que desta forma, conseguiram manter a atenção concentrada por toda a atividade. 
As atividades propostas nas disciplinas foram bastante distintas: uma utilizou de recursos mais tecnológicos e outra o "fazer para aprender", de maneira mais artesanal. Independentemente das intervenções feitas, a maioria dos estudantes gostaram das propostas e se beneficiaram ao aprender o conteúdo a partir do seu estilo de aprendizagem. Sendo assim, compreende-se que é necessário romper com a posição de estudante-passivo, mostrando aos estudantes na prática como o conhecimento pode ser adquirido de modo mais fácil e interessante quando eles se apropriam do processo de aprendizagem.

Para a obtenção de dados mais precisos da efetividade da utilização de métodos de aprendizagem direcionados à amostra em estudo seria necessário mais tempo de aplicação da pesquisa e, um número maior de participantes também poderia influenciar a pesquisa e a dinâmica das aulas. A utilização do questionário se mostrou uma boa ferramenta para identificação das preferências e dificuldades de aprendizagem de estudantes universitários. Por ser prático existe a possibilidade de aplicá-lo no início de todo semestre, assim desenvolver aulas que atendam satisfatoriamente às necessidades dos estudantes.

\section{Referências}

BARROS, R.; MONTEIRO, A. R.; MOREIRA, J. A. M. Aprender no ensino superior: relações com a predisposição dos estudantes para o envolvimento na aprendizagem ao longo da vida. Rev. bras. Estud. pedagog. (online), Brasília, v. 95, n. 241, p. 544-566, set./dez. 2014.

BECKER, F. Educação e Construção do Conhecimento. 2.ed.Porto Alegre: Penso, 2012.

CERQUEIRA, T. C. S. Estilos de aprendizagem em universitários. Tese de Doutorado, Faculdade de Educação, Universidade Estadual de Campinas, Campinas, São Paulo, 2000.

DEWEY, J. Experiência e educação. Tradução Anísio Teixeira. São Paulo: Editora Nacional, 1971.

DORSEY, O. L., Pierson, M.J. A descriptive study of adult learning styles in a nontraditional education program. Lifelong Learning: An Omnibus of Practice and Research, 7, 8-11, 1984.

DUNN, R.; DUNN, K. The complete guide to the Learning Styles Inservice System. Boston: Allyn and Bacon, 1999.

DUNN, R. S.; DUNN, K.J. Learning styles/teaching styles: Should they . . can they . . be matched? Educational Leadership, 36, 238-244, 1979.

FELICETTI, V. L. Comprometimento do estudante: um elo entre aprendizagem e inclusão social na qualidade da educação superior. 298 f. Tese (Doutorado em Educação) - Pontifícia Universidade do Rio Grande do Sul, Rio Grande do Sul, 2011.

FREIRE, P. Cartas a Cristina: reflexões sobre minha vida e minha práxis. 2. ed. São Paulo: UNESP, 2003.

\begin{tabular}{l|l|l|l|l|l} 
(C) Rev. Inter. Educ. Sup. & Campinas, SP & v.7 & $1-15$ & $\mathrm{e} 021028$ & 2021 \\
\hline
\end{tabular}


JESUS, E. M. S.; SANTOS, D. V.; VIEIRA, M. L. C.; CARVALHO, A. A. Metodologias de ensino e os estilos de aprendizagem na graduação em farmácia: um estudo piloto. Revista on line de Política e Gestão Educacional, v.21, n. esp. 1, p. 621-639, out./2017.

LUDWIG, J.P. et al. Strategic planning: analysis of efficiency methodology applied through Likert Scale. Espacios, vol. 36, nº 16, 2015

MAZUROSKI Jr., A. et al. Variação nos estilos de aprendizagem: investigando as diferenças individuais na sala de aula. ReVEL. Vol. 6, n. 11, agosto de 2008.

MORIN, E. Os sete saberes necessários à educação do futuro. 10. ed. São Paulo: Cortez, Brasília. 2005.

NEGREIROS, F.; SILVA, E. H. B.; LIMA, J. A. Estilos de aprendizagem no ensino superior: um estudo com universitários ribeirinhos do Piauí. Revista Educação e Emancipação, São Luís, v. 9, n. 3, ed. especial, jul./dez. 2016.

REGO, T. C. Vygotsky: uma perspectiva histórico-cultural da educação. 12. ed. Petrópolis: Vozes, 2001.

REID, J. M. The learning style preferences of ESL students. TESOL Quarterly, 21(1), 1987.

SONAGLIO, A. L. B.; GODOI, C. K.; SILVA, A. B. Estilos de aprendizagem experiencial e aquisição de habilidades: um estudo com discentes de graduação em Administração em instituição de ensino superior. Administração: Ensino e Pesquisa. RIO DE JANEIRO, V. 14 No 1 P. 123-159, 2013.

TAPIAS, M. G.; CUÉ, J. L. G.; VIVAS, M.; RINCÓN, J. A. S.; GARCÍA, C. M. A.; DIOS, M. S. A. Estudio comparativo de los estilos de aprendizajes del alumnado que inicia sus estudios universitarios en diversas facultades de Venezuela, México y España. Revista Estilos de Aprendizaje, n.7, v.7, p.1-27, 2011.

ZANON, D. A. V.; OLIVEIRA, J. R. S.; QUEIROZ, S. L. O "saber" e o "saber fazer" necessários à atividade docente no ensino superior: visões de alunos de pós-graduação em Química. Ens. Pesqui. Educ. Ciênc. (Belo Horizonte), Belo Horizonte, v. 11, n. 1, p. 140-159, June 2009. 